\title{
A device for concurrent bilateral measurement of outer eyelid closures in the rabbit
}

\author{
SUSAN E. BRANDON, BRET LOGAN, NIGEL COX, and ALLAN R. WAGNER \\ Yale University, New Haven, Connecticut
}

\begin{abstract}
This paper describes a transducer that allows for the concurrent recording of outer eyelid closure on both the left and the right eyes of a rabbit. The device makes use of voltage induced across a current-carrying conductor when the conductor is exposed to a magnetic field perpendicular to its axis (the Hall effect). The transducer is relatively compact, inexpensive, and allows the animal to be loosely restrained.
\end{abstract}

This paper describes the design and properties of a transducer for recording eyelid closure from both eyes of a rabbit simultaneously. Closure of the outer eyelid or nictitating membrane of the rabbit eyeblink has been used extensively in analyses of Pavlovian conditioning, where the focus of most experimentation has been on the behavior of a single eye (see Patterson \& Romano, 1987, for a review). A distinctive feature of this conditioned response (CR), as it has been investigated in the rabbit, is that it is strongly lateralized, as is shown in studies that have measured closure on both eyes either concurrently or successively (see, e.g., Kettlewell, O'Connell, \& Berger, 1974; McCormick, Clark, Lavond, \& Thompson, 1982; Pearce, Montgomery, \& Dickinson, 1981; Salafia, Daston, Bartosiak, Hurley, \& Martino, 1974; Stickney \& Donahoe, 1983).

Recently, Brandon, Betts, and Wagner (1994) showed the potential usefulness of measuring eyelid closure CRs on both eyes concurrently and, to our knowledge, were the first to demonstrate discriminated lateralized conditioned responding. They observed that, although paraorbital shock applied to one eye region elicits a bilateral eyeblink unconditioned response (with the amplitude of the response being larger on the eye to which the stimulus is applied), a conditioned stimulus (CS) that regularly precedes the unconditioned stimulus (US) comes to elicit a $\mathrm{CR}$ that is largely unilateral. What Brandon et al. showed further was that, when one CS was paired with paraorbital shock to the right region and another CS was paired with paraorbital shock to the left region, the former came to elicit eyelid closure predominantly on the right eye, and the latter to elicit eyelid closure predominantly on the left eye.

The transducer described here has characteristics similar to those developed by Gormezano and his associates

The development of the device was supported in part by National Science Foundation Grant BNS-9121094 to A.R.W. N.C. is in the Yale Medical Instrument Shop. Correspondence concerning this article should be addressed to S. E. Brandon, Department of Psychology, P.O. Box 208205, Yale University, New Haven, CT 06520-8205 (e-mail: susan_brandon@quickmail.yale.edu). for the measurement of nictitating membrane movement (Gormezano \& Gibbs, 1988; Gormezano, Schneiderman, Deaux, \& Fuentes, 1962) but allows for monitoring closure on both eyes simultaneously. It was also designed so that it does not require that the animal's head be rigidly restrained.

\section{Description}

Figure 1 shows a restrained rabbit with the device on the dorsal surface of its head. In our laboratory, the rabbit is loosely restrained at the neck by holding it in a $51 \times$ $18 \times 14 \mathrm{~cm}$ Plexiglas box, from which its head protrudes. Also depicted in Figure 1 are devices for the delivery of

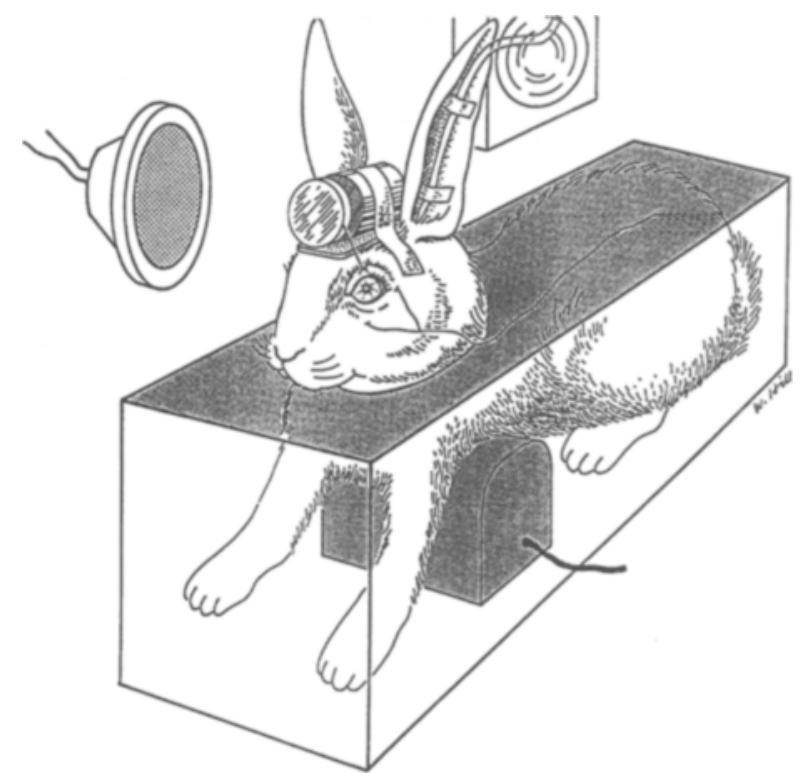

Figure 1. Schematic diagram of a restrained rabbit with the two-eye transducer placed on top of the animal's head. This lateral view shows how one wheel is attached with wheel strings to sutures in the lid of the animal's left eye. Also depicted are devices for the delivery of various stimuli to the animal (an ear tube for delivery of air, a massager under the animal's chest for vibrotactual stimuli, a speaker for auditory cues, and a strobe light for visual cues). 


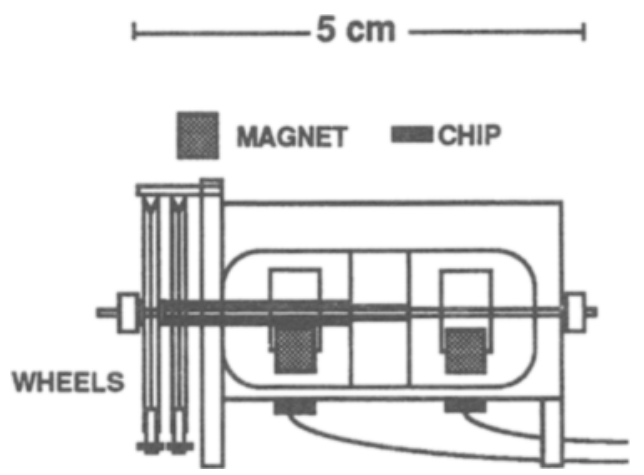

Figure 2. A lateral schematic of the device, with the outer casing removed. The diagram shows the two magnets, attached to two independent axles, below which are the Hall-effect chips and attached wires. The pulley wheels are on designated axles, parallel to each other.

various stimuli to the animal (an ear tube for delivery of air, a massager under the animal's chest for vibrotactual stimuli, a speaker for auditory cues, and a strobe light for visual cues). The restraint allows the animal to move its head in all directions. The transducer is secure enough, however, that we are able to simultaneously record elicited head-startle responses of the rabbit to controlled puffs of air directed to the auditory canal (Falls \& Wagner, 1991). The rapid head-jerk characteristic of the air-puff-elicited startle requires considerable freedom of the animal's head, which is allowed by the compactness and stability of the dual eyeblink transducer.

The casing of the unit consists of a clear Plexiglas cylinder, $3.8 \mathrm{~cm}$ (length) $\times 3.3 \mathrm{~cm}$ (diameter). There are two pulley wheels, parallel to each other at the front end of the cylinder, attached to nested axle shafts. A thin thread runs along a groove in each pulley wheel. One end of each string is attached to the wheel with a small screw, which also serves as a counterweight. The other end is hooked to a sutured loop in the edge of each eyelid.

The dorsal area of the animal's head on which the device rests is closely shaved prior to placement of the transducer. Typically, the shaving must be repeated about once a week. The device is secured to the rabbit's head at the base with two-sided, 3-mm Permatype tape and across the top with clear $3 \mathrm{M}$ Transpose adhesive tape. Clear tape is used so that the position of the magnet can be observed when the device is in place, which facilitates proper placement of the unit on the animal, as is described below. Although we routinely remove the device at the end of the experimental sessions, the Plexiglas is sturdy enough that the transducer conceivably could be more permanently attached to the skull-for example, in conjunction with plug assemblies for electrode placement.

The inside of the device, with the clear Plexiglas cylinder cover removed, is shown from a side view in Figure 2. Running through the center of the device is a narrow $(0.8-\mathrm{mm}) 23$-gauge stainless steel tube, one end of which is attached to the front wheel, the other end of which is attached to the rear of the housing. A polycarbonate magnet (rare earth neodenium ND32C7006B, from Permag in Hicksville, NY), inserted into a Plexiglas holding block, is attached to this tube. When the front wheel moves, the magnet is displaced across the face of a Hall-effect integrated circuit chip, which lies directly below the floor of the device. The inner wheel fits over a larger (18-gauge) stainless steel tube that serves as the housing for the smaller tube. Movement of the inner wheel displaces a second magnet across the face of a second integrated circuit chip. Both tubes are encased in an even larger (15-gauge) stainless steel tube that is secured at both ends to the Plexiglas. The clear Plexiglas outer casing is slid over the

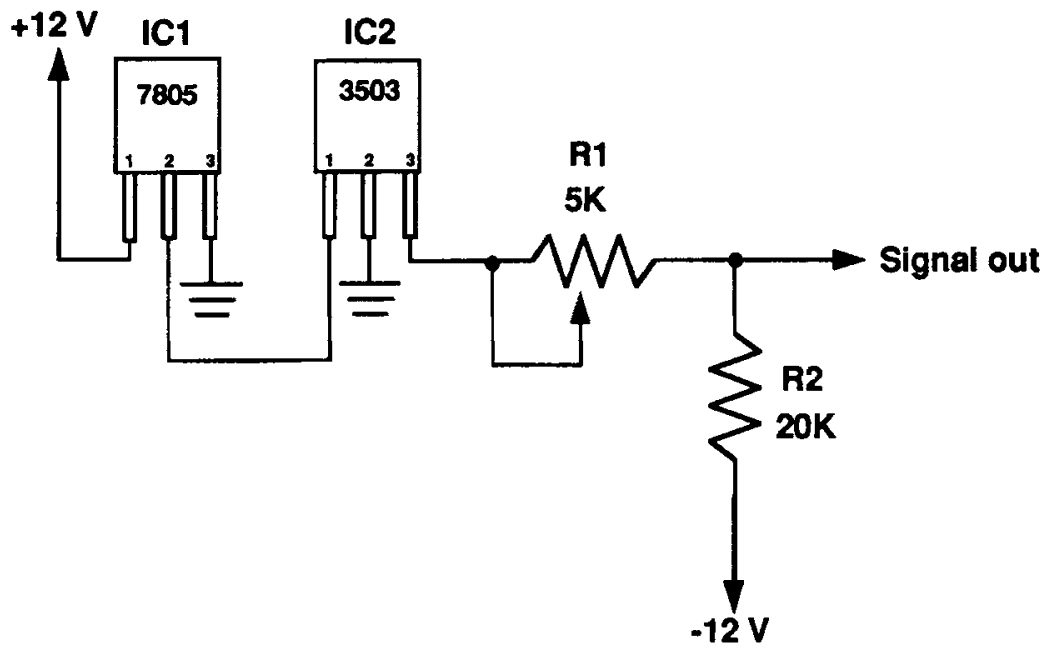

Figure 3. Hall-effect chip circuit. IC1 is a 7805 voltage regulator (Radio Shack, No. 2761770). IC2 is a Hall-effect chip (Newark Electronics, No. UGN3503U). 


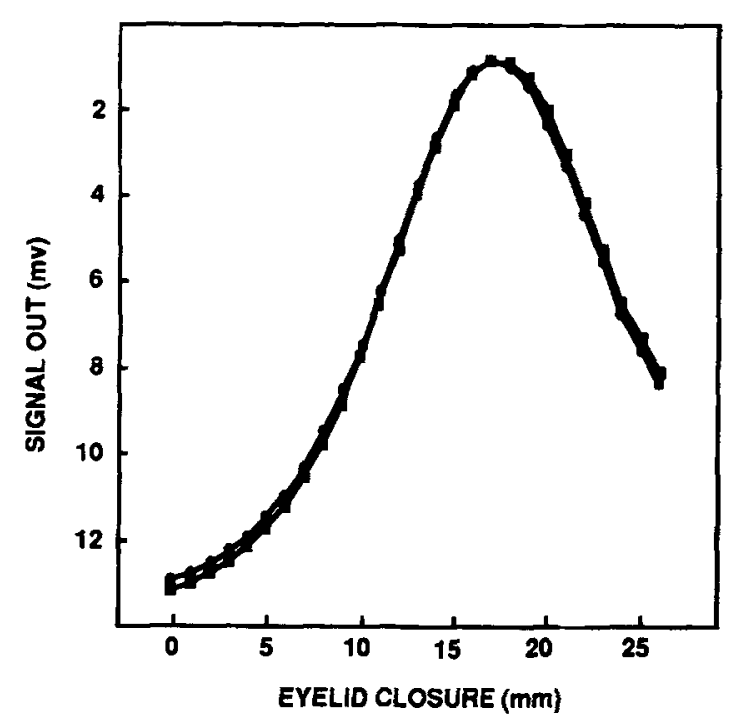

Figure 4. The functions show the relationship between the signal out (in millivolts) and the amount of eyelid closure (in millimeters) for two wheels of a single transducer. Each wheel was turned a radius of $180^{\circ}$.

main housing block up to the point where the pulley wheels are attached, allowing only for the exit of the wires attached to the Hall-effect chips at one end. The clear Plexiglas permits the operator to see the arrangement of components inside the device, which allows for the wheels and magnets to be correctly aligned in the baseline position when the device is attached to the animal. The startlemovement transducer referred to above can be placed inside the device, above the Plexiglas block, with its wires exiting from the rear of the cylinder cover, together with those from the Hall-effect chips.

\section{Electronics}

The Hall effect refers to the voltage created across a current-carrying conductor when the conductor is exposed to a magnetic field perpendicular to its axis. This voltage, although small (typically in the range of microvolts), is proportionally related to the magnetic field strength and, therefore, allows electronic measure of the strength and orientation of a magnetic field.

A great number of integrated circuit packages implementing the Hall effect are presently available, most of which are rugged three-terminal chips priced at around $\$ 1$. The chip used in this design (Newark Electronics, part no. UGN3503U) is typical, operating from a $5-\mathrm{V}$ power supply and requiring approximately $9 \mathrm{~mA}$ of current. It has a bandwidth of $23 \mathrm{kHz}$ and provides an output impedance of $50 \Omega$. It has a neutral state output (i.e., one with no significant magnetic field nearby) of approximately $2.5 \mathrm{~V}$, which varies between 0 and $5 \mathrm{~V}$, depending on the polarity and strength of the applied magnetic field. The sensitivity is typically $1.30 \mathrm{mV} / \mathrm{G}$.

The circuitry of the system is shown in Figure 3. The supporting electronics include $\mathrm{a}+12-\mathrm{V}$ dc supply, which is regulated to the $+5 \mathrm{~V}$ required by the Hall-effect chip using a 7805 voltage regulator (Radio Shack, No. 2761770). A - 12-V supply is used (through R2) to force the quiescent point output through potentiometer $\mathrm{R} 1$ to $0 \mathrm{~V}$. This allows a simple means of zero-setting the output of each Hall-effect device independently by adjusting $R 1$.

\section{Calibration}

Figure 4 indicates the relationship between the output signal and the degree of eyelid closure for two wheels on a single transducer calibrated separately in this laboratory. The baseline was adjusted (via R1) so that, when the magnet was in a vertical position, facing the Hall-effect chip, the signal out was $0 \mathrm{mV}$. The calibration then began with the magnet at an angle of almost $90^{\circ}$ from the chip and moving in a clockwise direction until it had rotated $180^{\circ}$. (Rotation of the wheel was accomplished by pulling the string in a vertical direction in 0.5 -mm steps.) As can be seen from Figure 4, there was very little difference between the output signals of the two wheels. The signal out peaked when the magnet swung across the face of the chip, and the broad peak of the curve occurred when the magnet was beginning a $180^{\circ}$ rotation facing away from the chip. Figure 5 shows a portion of a similarly calibrated output signal, fitted with a straight line, across an eyelid closure of roughly $10 \mathrm{~mm}$. The straight line fit accounted for $98 \%$ of the variance in the output signal.

\section{Experimental Recordings}

We have assumed a linear output in most instances of measuring CRs, which tend to be about 4 to $8 \mathrm{~mm}$ in amplitude. Representative data from a published experiment (Brandon et al., 1994, Experiment 2) in which the device was used are shown in Figure 6. Recordings were made from two eyes of a well-trained rabbit. The CSs were

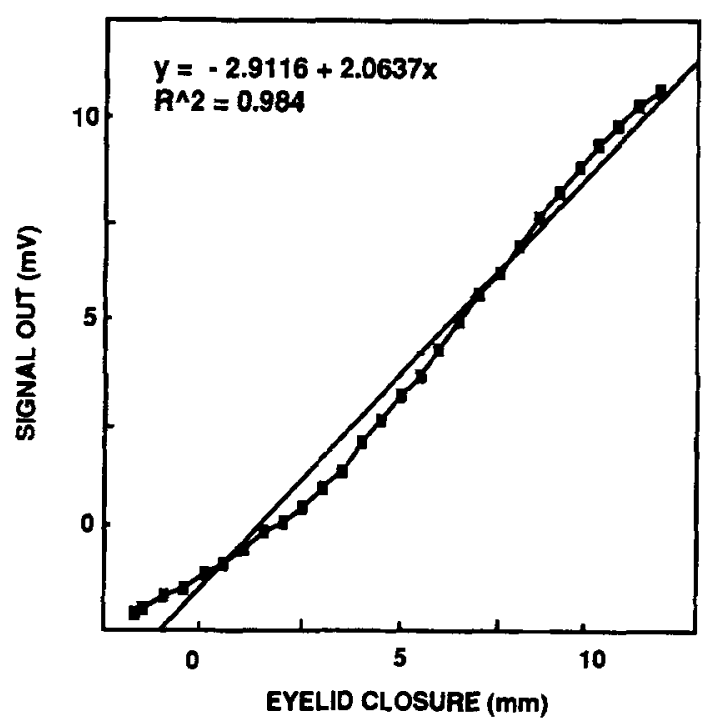

Figure 5. The relationship between the signal out (in millivolts) and amount of eyelid closure (in millimeters) across a range of approximately $10-\mathrm{mm}$ eyelid closure. 
a)

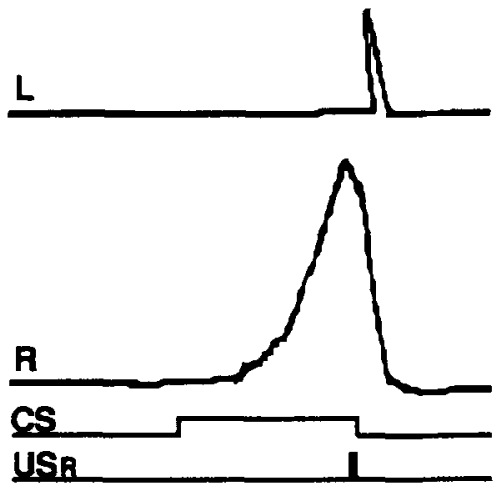

b)

$\mathbf{L}$

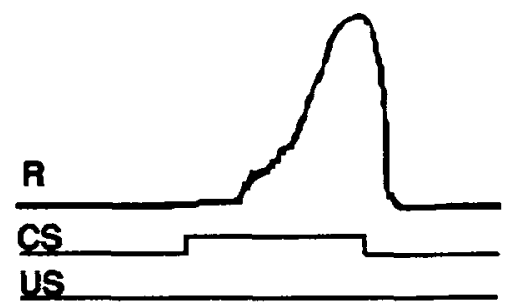

c)
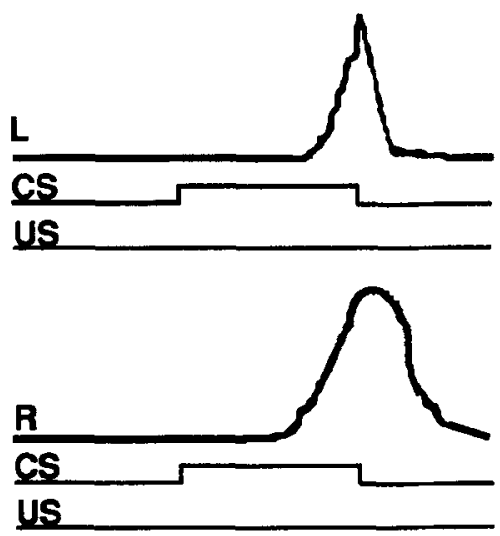

Figure 6. Recordings taken from the two eyes of a single rabbit. Panel a: A single conditioned stimulus (CS) had been paired with an unconditioned stimulus (US) applied to the right paraorbital region only. On the trial shown, this $C S$ was presented and coterminated with its associated US. Panel b: The same CS presented in the absence of a US. Panel c: Two CSs had been trained, one with a US applied to the left paraorbital region, and one with a US applied to the right paraorbital region. On the trial shown, the two CSs were presented concurrently and without their associated USs.

a light and a vibrotactual stimulus, each $1,050 \mathrm{msec}$ in duration. Each CS coterminated with a 50 -msec train of $100 / \mathrm{sec}, 4-\mathrm{mA}$ square-wave shock pulses produced by a constant-current generator and delivered through two 32-gauge stainless steel sutures implanted in the skin about the orbit of the subject's eye. One suture was located approximately $5 \mathrm{~mm}$ ventral to the extreme nasal extent, and the other approximately $5 \mathrm{~mm}$ caudal to the extreme lateral extent of the eye. One CS had been paired with a paraorbital shock applied to the left region, and another CS had been paired with a paraorbital shock applied to the right region. Signals from each eye were recorded on a two-channel polygraph (R511 SensorMedic). In each box, the top channel shows eyelid closure on the left eye, and the bottom channel shows eyelid closure on the right eye.

Panel a in Figure 6 shows data recorded for a rabbit that was presented with a CS that had been paired previously with a US to the right eye, when that CS was followed again with a right-eye US. There was a large $C R$ to the CS on the right eye (eyelid closure began well before the delivery of the US), and virtually no CR on the left eye, although the unconditioned response was bilateral (but larger at the shocked location). We typically have a response criterion of $0.5-1.0-\mathrm{mm}$ eyelid closure, so that a response as small as that indicated here on the contralateral eye would not reach this criterion. Panel $b$ shows the results of presentation of the same CS, but with the US omitted. Again, there was a considerable CR on the right eye and virtually no response on the left. Panel c shows the results of presentation of a complex CS, which consisted of one CS that had previously been paired with a left-eye US and another CS that had previously been paired with a right-eye US. On this trial, the animal showed a CR on both eyes.

It should be noted here that this degree of laterality has been observed, in this laboratory, in experiments in which there are two CSs, each paired with a different paraorbital US. In experiments in which there are three CSs, two paired with a different paraorbital US and a third paired with no US, we have observed a somewhat greater likelihood of response on the contralateral eye, although this response is of smaller amplitude and occurs less frequently than the response on the eye ipsilateral to the location of the US application (see, e.g., Brandon et al., 1994, Experiment 3).

Comparisons across similarly designed experiments in this laboratory have not shown any apparent differences in onset latency or peak amplitude of eyelid closure responses corresponding to the use of the two-eye transducer described here, as opposed to the one-eye transducer that we have been using previously (see also Gewirtz, Brandon, \& Wagner, 1998). For comparisons of response frequency measures using a one-eye versus a twoeye transducer, see Brandon et al. (1994, Experiments 1 and 2 , respectively).

\section{Conclusion}

The two-eye transducer described here has several advantages over existing single-eye transducers. It allows for simultaneous recording of lid closure on both eyes, so that one can take advantage of the lateralized discriminative eyelid conditioning that the rabbit exhibits. It leaves the animal with considerable freedom to move 
its head, making possible the concurrent recording of an elicited startle response. The components are relatively inexpensive; the total cost of parts per unit is less than $\$ 20$, although the machining of the assembly adds to this cost. The unit is lightweight, durable, stable, and requires virtually no maintenance. We have used it in this laboratory for over 5 years and have found it to be a reliable instrument.

\section{REFERENCES}

Brandon, S. E., Betts, S. L., \& Wagner, A. R. (1994). Discriminated, lateralized, eyeblink conditioning in the rabbit: An experimental context for separating specific and general associative influences. Journal of Experimental Psychology: Animal Behavior Processes, 20, 292-307.

FALLS, W. A., \& WAGNER, A. R. (1991). Airpuff-elicited startle in the rabbit (Oryctolagus cuniculus). Unpublished manuscript.

GewirTz, J. C., Brandon, S. E., \& WaGner, A. R. (1998). Modulation of the acquisition of the rabbit eyeblink conditioned response by conditioned contextual stimuli. Journal of Experimental Psychology: Animal Behavior Processes, 24, 106-117.

Gormezano, I., \& GiBBs, C. M. (1988). Transduction of the rabbit's nictitating membrane response. Behavior Research Methods, Instruments, \& Computers, 20, 18-21.
Gormezano, I., Schneiderman, N., Deaux, E., \& Fuentes, I. (1962). Nictitating membrane: Classical conditioning and extinction in the albino rabbit. Science, 138, 33-34.

Kettlewell, N. M., O’Connell, M. F., \& Berger, L. H. (1974). Bilateral nictitating membrane conditioning in rabbits under asymmetrical levels of cutaneous afferent activity. Physiology \& Behavior, 13, $27-33$.

McCormick, D. A., Clark, G. A., Lavond, D. G., \& Thompson, R. F. (1982). Initial localization of the memory trace for a basic form of learning. Proceedings of the National Academy of Sciences, 79, 2731-2735.

Patterson, M. M., \& Romano, A. G. (1987). The rabbit in Pavlovian conditioning. In I. Gormezano, W. F. Prokasy, \& R. F. Thompson (Eds.), Classical conditioning (pp. 1-36). Hillsdale, NJ: Erlbaum.

Pearce, J. M., Montgomery, A., \& Dickinson, A. (1981). Contralateral transfer of inhibitory and excitatory eyelid conditioning in the rabbit. Quarterly Journal of Experimental Psychology, 33B, 45-61.

Salafia, W. R., Daston, A. P., Bartosiak, R. S., Hurley, J., \& MarTINO, L. J. (1974). Classical nictitating membrane conditioning in the rabbit (Oryctolagus cuniculus) as a function of unconditioned stimulus locus. Journal of Comparative \& Physiological Psychology, 86, 628-636

Stickney, K. J., \& Donahoe, J. W. (1983). Attenuation of blocking by a change in US locus. Animal Learning \& Behavior, 11, 60-66.

(Manuscript received November 7, 1996; revision accepted for publication February 6, 1997.) 